\title{
All Sexed Up: \\ a resposta de mulheres lésbicas negras jovens ao sexo (mais) seguro em Johannesburg, África do Sul*
}

| 'Zethu Matebeni |

| Tradução: ${ }^{2}$ Thais Medina Coeli Rochel de Camargo |

| Revisão Técnica: ${ }^{3}$ Kenneth Rochel de Camargo Jr; ${ }^{4}$ Laércio Fidelis Dias |

Resumo: A saúde sexual de mulheres lésbicas não é um tema frequentemente discutido em nossas sociedades. As questões de saúde da mulher são classificadas sob uma única categoria abrangente e excluem algumas das preocupações específicas de mulheres lésbicas, que, em geral, não têm o mesmo comportamento em relação à saúde que as mulheres heterossexuais. Esta tendência se deve a uma série de razões, entre as quais: falta de conhecimento sobre saúde e risco sexuais lésbicos, medo de estigmatização pel os prestadores de serviço e o processo de "se assumir" (coming out) para esses profissionais, que além de desconhecido, é, al gumas vezes, hostil. Além disso, a pouca pesquisa sobre lésbicas e saúde lésbica na África do Sul torna difícil para as mulheres que assim se autoclassificam saberem que questões de saúde sexual as afetam especificamente, bem como onde e de que forma lidar com certos problemas. Existe uma percepção equivocada e generalizada de que questões de sexo seguro não afetam mulheres lésbicas tanto quanto mulheres heterossexuais. 0 artigo apresenta as visões de um grupo de mulheres de 18 a 35 anos que se autoidentificam como lésbicas na África de Sul. Por meio de questionários autoaplicados e discussões, essas mulheres partilham suas experiências e pensamentos sobre sexo lésbico (seguro) e como elas têm-se relacionado e continuam a se relacionar sexualmente com outras mulheres no momento de H IV e Aids.

> Palavras-chave: Lésbica; gênero; identidade; sexualidade; HIV e AIDS, África do Sul.

\author{
${ }^{1}$ Doutoranda do Wits Institute \\ for Social Economic Research \\ (WISER) em Johannesburg. Sua \\ pesquisa busca compreender e \\ explorar identidades e \\ sexualidades de lésbicas \\ negras naquela cidade. Já \\ trabalhou como coordenadora \\ de pesquisa na campanha \\ nacional contra HIV e Aids, \\ tuberculose e DST do governo \\ sul-africano. \\ ${ }^{2}$ Graduanda em Ciências \\ Sociais - FGV-RJ. \\ ${ }^{3}$ Profesor adjunto do IMS-UERJ. \\ ${ }^{4}$ Doutor em Antropologia pelo \\ Programa de Pós-Graduação \\ em Antropologia Social \\ (PPGAS) da Universidade de São \\ Paulo (USP).
}


A questão da identidade lésbica, ou quem as lésbicas são e o que lésbica significa, não foi suficientemente explorada na África do Sul. Enquanto al guns vêem essa identidade como problemática em contextos africanos (KEN D ALL, 1998), muitas mulheres em relacionamentos eróticos com pessoas do mesmo sexo adotam e se identificam nestes termos (BLYTH , 1989). Com a adoção da Constituição mais progressista, muitos sul-africanos têm o privilégio de afirmar uma série de identidades e de escolher abertamente experiências com as quais se sentem confortáveis, sabendo que serão protegidos pela lei. Contudo, pouco se sabe sobre suas identidades e as implicações dessas identidades e escolhas em suas vidas cotidianas. Este artigo discute identidades sexuais entre um grupo de mulheres que se autoidentificam como lésbicas ou homossexuais, e como suas identidades sexuais afetam suas sexualidades.

As discussões sobre identidade e uso de certa terminologia para descrever membros da comunidade lésbica, bem como as implicações de certas identidades na experiência sexual, são parte de um estudo em andamento. M uito dessas reflexões não se encontra neste artigo. As mulheres que são apresentadas aqui fazem parte de uma organização ativista lésbica e el as próprias têm interesse em questões e políticas que afetam as comunidades gay, lésbica, bissexual, transgênero etransexual em Joanesburgo.

É altamente incomum para organizações que trabalham com as comunidades lésbica, gay e trans na África do Sul organizar eventos públicos para mostrar seu trabalho para seu público-alvo. I sso, contudo, ocorreu numa tarde desábado, numa área histórica de J ohannesburg, sede da corte constitucional. N aquele dia, cerca de 400 membros da comunidadeencontram-sepresentespara ver o quesuasorganizações oferecem epara participar do diálogo sobre casamento entrepessoas do mesmo sexo.

Após algum tempo, tendo algumas pessoas perdido interesse nos debates e acontecimentos do evento, comecei a conversar com algumas mulheres lésbicas que conheço destes círculos. Como nossas redes são pequenas, tomamos conhecimento dos relacionamentos sexuais e de vários aspectos das vidas privadas umas das outras. Estes passaram a ser o tópico da discussão, com al gumas mulheres do grupo expressando seu interesse umas nas outras. Foi neste momento que pedi a al guns indivíduos que considerassem discutir suas experiências e relações sexuais. D epois de explicar os tipos de questões e interesses que gostaria de explorar, muitas das mulheres com quem costumo me encontrar afirmaram seu interesse em falar 
sobre sexo. Todas nós concordamos que as discussões sobre sexo e sexualidade são tabus em nossas sociedades, cuja conseqüência é o silêncio (mesmo entre nós) sobre estes comportamentos. Enquanto o silêncio encobre esses debates, todas nós secretamente partilhamos e nos vangloriamos de nossas múltiplas experiências sexuais. Algumas compartilham a esperança de que suas parceiras estáveis nunca fiquem sabendo desses debates. São essas mulheres e conversas que informam o presente artigo.

\section{Sexualidade na África do Sul pós-apartheid}

Com a emergência da epidemia de H IV eAids e as preocupações relativas à saúde pública e as crises no subcontinente, o debate sobre sexualidade na África do Sul se desenvolveu sobretudo no âmbito da epidemia e da ameaça de violência sexual (SH EFER; POTGEITER, 2006). M uitas pessoas em relacionamentos eróticos com pessoas do mesmo sexo não escaparam da epidemia ou da violência sexual endêmica que afeta os sul-africanos. Embora muito se tenha escrito sobre a sexualidade de homens gays e sua interação com os debates sobre HIV e Aids, continua a existir um silêncio sobre relacionamentos com pessoas do mesmo sexo femininos, e como H IV e Aids afetam mulheres. A crença de que mulheres em relacionamentos com pessoas do mesmo sexo têm risco baixo ou inexistente de contrair H IV e outras doenças sexualmente transmissíveis continua a dominar. Essa crença também menospreza ou ignora aquelas que se encontram tanto em relacionamentos homossexuais quanto em heterossexuais, bem como os riscos potenciais de infecção nestes tipos de parcerias.

O s efeitos da violência sexual são amplamente sentidos dentro da comunidade lésbica em J ohannesburg, sendo grande o número de mulheres vítimas de crimes deódio a ataques sexuais violentos, al guns dos quais levam à infecção por H IV ou mesmo à morte (M U H O LI, 2004). A comunidadelésbica negra em J ohannesburg passou por muitas mortes de mulheres lésbicas jovens e ativas que morreram de complicações ligadas à Aids. D ebates sobre H IV eAids, ecomo sobreviver a crimes de ódio e estupro continuam a ser discussões difíceis e muito emocionadas em nossos círculos, enquanto continuamos a buscar espaços e recursos que são direcionados a nós e a nossas experiências cotidianas. Esses espaços deixam de existir apesar da proteção aos direitos sexuais, garantida pela Constituição, e seu reconhecimento dos relacionamentos homossexuais. A África do Sul continua 
altamente homofóbica, patriarcal e heterossexista, o que se traduz na heterossexualidade como o ideal privilegiado acima de outras formas de sexualidade (W ELLS; PO LDERS, 2006). Esse privilégio concede toda a atenção e todos OS recursos a normas heterossexuais, ignorando e rejeitando a existência de outras sexual idades que lidam com os mesmos desafios que o ideal heterossexual.

Entre muitos sul-africanos negros, a homossexual idade é vista como "nãoafricana" e como algo importado do 0 cidente. Essa crença é perpetuada pela fal ta de visibilidade das pessoas negras - ao contrário do que ocorre com pessoas brancas - que se relacionam abertamente com pessoas do mesmo sexo; a rejeição de relacionamentos entre pessoas do mesmo sexo, que, apesar de existirem, não são designados relacionamentos gays ou lésbicos; e a rejeição inequívoca de relacionamentos entre pessoas do mesmo sexo em comunidades negras. 0 s que se encontram em relacionamentos com pessoas do mesmo sexo nessas comunidades sentem o impacto dessa crença, e muitos passaram por ataques violentos (GREVISSER, 1994).

0 medo e o silêncio "forçado" entre mulheres lésbicas negras levaram muitas delas a se calarem sobre sua sexualidade e suas experiências. Ações para encorajar mulheres lésbicas negrasa reivindicarem seus espaçose a falar sobresuas sexualidades são mínimas e, quando existem, requerem enormes esforços. Essas ações incluem, mas não se limitam a: constante encorajamento a fal ar sobre essas questões; esforços severose reforçados para proteger 0 anonimato ea confidencialidadedeinformantes; ea criação ou organização deespaços seguros on de mulheres lésbicas negras possam se reunir e manter o diálogo sem medo, vitimização ou visibilidade forçada.

\section{$M$ etodologia}

U ma razão frequentemente citada para não se estudar lésbicas é que elas têm sido tradicional mentemenos visíveis do que homens homossexuaise, portanto, menos acessíveis para pesquisadores. (ZIM M ERM AN , 1981) C omo lésbicas são invisíveis, não-documentadas e estigmatizadas em muitas sociedades, o tema torna-se difícil de ser pesquisado. Muitas delas são inacessíveis também porque não são politicamente engajadas, mantêm sua identidade em segredo ou são socialmente isoladas. Um esforço foi feito, naquelas tardes de sábado na sede da corte constitucional em Johannesburg, para recrutar e contatar mulheres lésbicas reservadas e politicamente periféricas. I sso foi feito por meio da distribuição de 
questionários auto-aplicados que garantiam anonimato e confidencialidade para os informantes. C ada entrevistada recebeu um questionário e se dirigiu a um canto silencioso onde preencheu sozinha seu questionário. Em muitos casos, aquelas que participaram da entrevista receberam os questionários, os levaram para casa e, após preenchêlos, os enviaram para a pesquisadora.

D uas cópias de um formulário de consentimento informado e uma folha com informações acompanhavam cada questionário, um para ser devolvido à pesquisadora e o outro para ser mantido pela informante. Estes não estavam afixados ao questionário para garantir anonimato. A população-alvo do estudo foi definida como todas as mulheres que atualmente se encontram em ou que estiveram em relacionamentos sexuais com outras mulheres. D os 30 questionários distribuídos, um total de 23 foi recebido. Q uatro informantes completaram um formulário de consentimento informado masnão retornaram o questionário. Todas as entrevistadas eram mulheres negras da área de J ohannesburg.

A idade das informantes variou de 19 a 34 anos, com uma distribuição igual de pessoas entre os grupos de idade: 18-21, 22-25 e 26-29. Q uatro estavam no grupo de idade de 30 a 33 anos e uma tinha 34 anos. Em relação à ocupação, a maioria das entrevistadas encontra-se empregada $(n=8)$, cerca de um terço são estudantes empregadas e apenas três são estudantes em tempo integral. Q uatro relataram estar desempregadas e mais da metade encontra-se atualmente em relacionamentos ou têm uma parceira sexual em tempo integral. Apenas seis informantes relataram estar solteiras. Estar solteira não significa necessariamente queo indivíduo não tenha um parceiro sexual. Como será apresentado na seção de "discussão", mesmo aquelas que relatam estar solteiras têm parceira(s) sexual(ais), que em muitos casos são relações casuais. Elas se referem usualmente àquelas engajadas em relacionamentos afetivo-sexuais como estando partnered. ${ }^{1}$

Para obter expressões de autoidentidade, perguntou-se às informantes "que palavra você mais usa para descrever sua orientação sexual?". Várias opções foram incluídas. Q uase todas as informantes $(n=19)$ identificaram-se como lésbicas. D estas, duas afirmaram preferir se definir como mulher queama mulher (M AM ), ${ }^{2}$ apesar de ambas terem marcado a opção "lésbica", termo comumente usado em círculos de mulheres em relacionamentos com pessoas do mesmo sexo em J ohannesburg. D uas outrasinformantes preferiram seidentificar como homossexual e um número igual preferiu não se identificar ou escolheu a categoria "outro". 


\begin{tabular}{|c|c|}
\hline VARIÁVEL & $N$ \\
\hline Idade & 23 \\
\hline $18-21$ & 6 \\
\hline $22-25$ & 6 \\
\hline $26-29$ & 6 \\
\hline $30-33$ & 4 \\
\hline $34-37$ & 1 \\
\hline Autoidentificam-se como... & 23 \\
\hline Lésbica & 19 \\
\hline Homossexual & 2 \\
\hline Mulher que ama mulher & 6 \\
\hline \multicolumn{2}{|l|}{ Papel desempenhado (role-play) } \\
\hline Butch & 6 \\
\hline Femme & 9 \\
\hline Nenhum/outro & 6 \\
\hline Ocupação/situação de emprego & 23 \\
\hline Empregada & 8 \\
\hline Desempregada & 4 \\
\hline Estudante & 3 \\
\hline Empregada/estudante & 4 \\
\hline Outro & 1 \\
\hline Situação de relacionamento & 23 \\
\hline Solteira & 6 \\
\hline Partnered & 13 \\
\hline Outra & 4 \\
\hline
\end{tabular}

Também se perguntou às informantes seelas assumem al gum papel (relacionado a gênero) ou se usam outras formas para se descrever. Seis de 20 informantes que responderam a essa pergunta se descreveram como butch e nove se descreveram como femme. Em J ohannesburg, muitas mulheres assumem a identidade lésbica uma vez tendo se envolvido sexualmente com outra mulher. Além disso, uma mulher é vista como lésbica quando se sabe ou se percebe que ela se envolveu sexual mente com uma mulher da comunidade. Entremulheres maisjovensquese identificam como lésbicas, papéis butch efemmesão enfatizados. Estes se referem a papéis degênero de masculinidadee feminilidade, respectivamente, mas apresentam um estilo sexual muito forte e "erótico" num relacionamento butch-femme 
(WIERIN GA, 2005). É normal conversar com uma mulher e ela direta e

abertamente referir-se a si mesma como femme. Existem vários termos locais que são usados dentro da comunidade "lésbica" para se referir a lésbicas que desempenham papéis butch e femme.

\section{D iscussão}

Existem vários "ideais" e ideias sobre como mulheres lésbicas pensam e conferem sentido ao sexo. Todas as informantes apresentaram o sexo de forma positiva como algo que é apreciado, prazeroso e íntimo. Frases e conceitos tais como "paixão, divertimento, prazer, sentimentos, ligação, proximidade, satisfação, íntimo, expressão de amor e compartilhamento" entre duas pessoas foram usualmente usadas para dar sentido ao que elas pensavam sobre sexo. A penas uma informante pensava que sexo estava ligado a um acordo comum (no sentido de consentimento) entre os parceiros. 0 utra acreditava que sexo era particular "entre minha parceira e eu". Algumas informantes pensavam que sexo estava ligado a quem elas eram. Como disse uma informante, "ele [sexo] afirma minha orientação sexual" e outra afirmou que sexo significa "ser eu mesma".

0 questionário pedia às informantesquelembrassem da primeiravez quefizeram sexo com uma mulher ecomo foi. A maioria relatou ter tido seu primeiro encontro sexual com uma mulher entre 14 e 17 anos. Apenas duas entrevistadas tinham iniciado sexo com umamulher antes de 13 anos deidade. Ao descrever sua primeira experiência sexual com uma mulher, algumas informantes relataram que foi "chocante", outras relataram que foi "assustadora", pois não sabiam o que fazer.

Foi assustador, eu não tinha certeza se iria satisfazêla, mas acabou sendo lindo. [lésbica, 26]

Chocante e estranho mas identificou quem eu sou e me motivou a ser eu mesma. [lésbica, femme, 21]

Chocante para mim que ela me fez sentir daquela forma. [lésbica, butch, 26]

A maioria dasinformanteslembrou experiências "agradáveis, ótimas, fantásticas". A pesar dos sentimentos ou experiências fantásticos eótimos, al gumas informantes acreditavam que, por não saberem o que fazer, estavam nervosas ou assustadas.

Foi bom, extraordinário. [butch, 28].

Ótimo. Algo que eu nunca tinha experimentado antes. Foram fogos de artifício. [femme, 30]. 
Fantástico e relaxante, mas um pouco assustador se você não sabe o que fazer. [femme, 20].

Eu estava assustada, foi doloroso e eu chorei. [femme, 23].

Para entender a história sexual eos parceiros sexuais, perguntou-seàs informantes o número deparceiros sexuais quetiveram em toda a vida. Estes não foram agregados por sexo biológico (homem ou mulher). Além disso, nesse questionário não se perguntou às entrevistadas se elas já estiveram ou estão com um homem. D iscussões sobrehistória sexual eparceiros estão sendo exploradas num estudo em andamento e não teria condições de ser explorado neste artigo.

\section{Tabela 2 - Informação e atividade sexual das informantes}

\begin{tabular}{l|c}
\hline \multicolumn{1}{c|}{$\begin{array}{c}\text { Variável } \\
\text { Idade no primeiro encontro sexual com uma } \\
\text { mulher }\end{array}$} & $N$ \\
\hline 13 ou menos & 2 \\
\hline $14-17$ & 8 \\
\hline $18-21$ & 4 \\
\hline $22-25$ & 3 \\
\hline Número total de parceiros sexuais & 23 \\
\hline 1 a 5 & 8 \\
\hline 6 a 10 & 4 \\
\hline 11 a 15 & 5 \\
\hline Mais de $20 \quad$ informantes & 4 \\
\hline Não se lembra/ nắo tem certeza & 2 \\
\hline Número de parceiros sexuais atuais entre & 23 \\
\hline 1 & 13 \\
\hline 2 & 3 \\
\hline 4 ou mais & 4 \\
\hline
\end{tabular}

Entre as informantes, a maioria tinha tido entre um e cinco parceiros sexuais em suas vidas. Seis delas tiveram mais do que 20 parceiros em suas vidas, duas das quais não se lembravam ou tinham perdido a conta. Contrariamente ao que se acredita sobre comportamento sexual entre lésbicas em Johannesburg, a maioria relatou uma única parceira sexual atual, não múltiplos parceiros. $M$ ais da metade das informantes relata ser monógama, com apenas uma parceira. 
Ao se observar as diferenças em relação a lésbicas queadotam papéis específicos, mais lésbicas femme (6), comparadas a quatro lésbicas butch, disseram estar partnered ou em um relacionamento. $D$ as que relataram estar solteiras, a relação de butch para femme foi de 1:3.

Tabela 3 - Parceiro(s) sexual(is) atual(is) segundo status de relacionamento e papel desempenhado

\begin{tabular}{l|c|c|c|c|c|c|c}
\hline & \multicolumn{4}{|c|}{ Número de parceiros sexuais atuais } & \multicolumn{3}{c}{ Papel desempenhado } \\
\hline & $\mathbf{1}$ & $\mathbf{2}$ & $\mathbf{3}$ & $\mathbf{4}$ & Butch & Femme & Outro \\
\hline Solteira & 3 & 3 & & & 1 & 3 & 2 \\
\hline Partnered & 9 & & 1 & 3 & 4 & 6 & 3 \\
\hline Outro & 1 & & 3 & & 1 & & 1 \\
\hline
\end{tabular}

0 número de parceiros sexuais é mais alto entre aquelas que relatam estar partnered do que entreasqueestão solteiras. D as 13 informantes que estão partnered, quatro têm três ou mais parceiros. Como mencionado anteriormente, as que estão soltei ras também têm parceiros sexuais.

Pediu-seàs informantes que falassem sobrea primeira vez quefizeram sexo com a última parceira sexual. Sexo com a última parceira foi iniciado de várias formas. Em al gumas situações, as entrevistadas relataram que o sexo foi planejado. I sso aconteceu sobretudo em situações em que indivíduos estavam namorando por algum tempo e então decidiram fazer sexo. Em outras situações, não foi planejado, apenas aconteceu após uma saída, ou foi o tempo certo ou o espaço era propício. Em resposta à pergunta sobre se houve negociações sobre sexo e quando elas se deram, a maioria das informantes $(n=11)$ relatou que o sexo foi negociado antes e depois de ter ocorrido. 0 ito relataram que não houve negociações ou discussões sobre sexo equatro relataram quefalaram sobre sexo apenas após esteter ocorrido. $D$ asquetinham falado sobre sexo, soubemos que as principais discussões incluíram: prazer, as preferências decada uma e como o sexo poderia ser melhorado; segurança e proteção contra doenças sexualmente transmissíveis (DST) e transmissão do HIV; e, por fim, discussões sobre penetração e como fazer sexo com uma mulher. 


\section{Sexo (mais) seguro com uma mulher: preocupações em relação ao HIV}

Tradicionalmente, pensava-se que mulheres lésbicas estavam livres de risco deDSTs, HIV e Aids. Resultados de um estudo realizado com homens gays e mulheres lésbicas na África do Sul mostram que isso não é verdade. Taxas de HIV autoreferido entre mulheres lésbicas mostram que $8 \%$ das que tinham sido testadas para H IV eram soropositivas (W ELLS; PO LDER, 2006).

Frente às discussões atuais sobre sexo seguro, transmissão de HIV e Aids, as entrevistadas deram respostas diversas à pergunta "o que si gnifica para você fazer sexo seguro com uma mulher?" U ma informante dissequeisso significava "nenhuma bissexual". Algumas falaram sobre "usar meios de proteção" e expressar seu amor por meio de formas seguras. O utras afirmaram saber e entender o risco de não praticar sexo seguro. $\mathrm{N}$ ove relataram nunca ter praticado sexo seguro com uma mulher. A maioria das querelataram ter em al gum momento praticado sexo seguro mencionou barreiras dentais ecamisinhas como os métodos debarreira mais usados. Algumas das que relataram praticar sexo seguro com uma mulher mencionaram os seguintes métodos:

nenhuma medida de proteção, apenas mãos e línguas. [femme, 21].

Preliminares e sexo nas coxas. [M AM, 20].

D e modo geral, usamos dedos, mas tudo que duas mulheres fazem, nós fazemos. [femme, 20].

[...] evitar a troca de fluidos. [femme, 30].

Aquelas que não praticam sexo seguro relatam que não o fazem porque:

$\mathrm{N}$ ão conhece lugares de onde obter medidas de segurança. [butch, 23].

Confiam uma na outra. [butch, 27].

Ignoramos que podemos ser infectadas. [butch, 26].

Sei que estou segura e minha parceira não está se envolvendo com mais ninguém; apenas com uma parceira. [femme, 30].

O utras pensam que:

N ão há recursos para sexo seguro para mulheres lésbicas. [M AM, 31]. 
Proteção lésbica é difícil de achar a não ser que você improvise. [femme, 23].

[que são] tomada[s] pelo momento - eu não penso na hora. [outra, 29].

Em conversas sobre sexo seguro entre mulheres, muitas lésbicas mencionam que as técnicas de sexo seguro disponíveis para mulheres lésbicas "não são sexy; são muito clínicas; elas estragam o momento; são muito feias/não-atraentese impossíveis de usar." U ma informante concordou com essas opiniões ao escrever: "Barreiras dentais (dental dams) - elas são um desastre, elas simplesmente não funcionam!"

A Aids deu início a discursos de perigo em relação ao sexo e como isso se relacionaà sexualidade das pessoas. Com altastaxas deinfecção por H IV na província e no país como um todo, uma pessoa têm de pensar duas vezes antes de praticar sexo desprotegido ou ser constantemente lembrada do H IV. A penas na província de Gauteng (onde a cidade de Johannesburg está situada), relata-se que a "prevalência deH IV estábem acima de 30\%". Em outras províncias a contaminação atinge uma porcentagem ainda maior. "A prevalência de HIV entre mulheres e entre pessoas entre 20 e 24 anos continuou a aumentar, com 29\% das mulheres sul-africanas infectadas." (Rampersadh, 2005).

Perguntou-se a todas as informantes se elas pensam sobre HIV eAID S equais são seus pensamentos sobre o assunto. Q uase todas as informantes (19) relataram pensar sobre e se preocupar com a epidemia. Alguns dos pensamentos e preocupações que as informantestinham incluem parceiras múltiplaseinfidelidade:

Se uma... é soropositiva, então há infidelidade. [butch, 27].

M inha parceira se envolvia com outras pessoas. Isso me preocupava até que eu fiz 0 teste. [femme, 19].

Eu tinha muitas parceiras e... pensando sobre contrair o vírus. [butch, 20].

O utrasmencionaram quetinham conhecimento de pessoas quesão soropositivas ou morreram de doenças relacionadas à Aids e queriam se proteger e proteger as suas parceiras.

Na minha família, seis membros morreram de HIV. [M AM, 31].

Como eu sou soropositiva, me preocupo em não infectar minha parceira. [femme, 28]. 
H ouve quem afirmasse que, apesar de pensar sobre e se preocupar com a epidemia, não conhecia seu status sorológico e fazia pouco para se proteger.

Eu [pensava] mas isso não nos preocupava tanto. [lésbica, 26].

Eu não sei se estou infectada ou não. [lésbica, 20].

A maior parte do tempo, eu não uso proteção. [lésbica, 24].

Eu sei que posso contrair doenças sexuais, mas não tenho feito nada para me proteger. [femme, 21].

O s demais relataram que não se preocupam muito porque "é para heteros" e "estou sempre conferindo o meu status sorológico e pratico sexo seguro".

Estes dados vão ao encontro daqueles nos quais $57 \%$ de mulheres lésbicas relataram que nunca estiveram em situação de risco, na qual pudessem ter contraído o H IV, e 53\% disseram que não acreditavam na possibilidade de ser tornarem soropositivas. Entretanto, taxas altas de H IV ainda se encontram presentes na comunidade lésbica. Estas taxas podem ser atribuídas a estupro, violência sexual, parceiras bissexuais e relação sexual sem proteção com homens (WELLS; KRUGER; JUDGE, 2006).

\section{Experiências e performance sexuais}

Com todas as preocupações que as informantes expressaram em relação a serem infectadas ou infectarem umas as outras, pode-se perguntar como essa questão se traduz em atitudes e comportamentos sexuais. A curiosidade girava em torno de se investigar se houve situações em que as entrevistadas pensaram que o sexo não foi tão bom ebel o como o retrataram no começo. Surpreendentemente, quando se perguntou o queera sexo ruim ese elastinham passado por isso em al gum momento, mais da metade (14) dasinformantes afirmaram já ter experimentado uma situação frustrante. M uitas descreveram sexo ruim como: "prazer não-mútuo; doloroso e apressado; quando a outra parceira é forçada a participar; quando minha parceira insere seus dedos em minha vagina; dormir com um robô; fazer sexo com al guém que não sabe o que está acontecendo; sexo unilateral; parceira egoísta; quando acaba ela não quer ser tocada ou goza antes de mim." Algumas relataram as consequências ou como acontecimentos de ordem sexual desagradáveisaconteceram com suas parceiras. Algumas mencionaram "traição"' como um resultado, outras 
performances e divertimento: não houve orgasmo ou prazer: "Eu estava sem poder e parei antes que a outra pessoa estivesse satisfeita". [lésbica, 20]. E ainda: "Eu senti como se tivesse dado tudo e recebido nada". [femme, 28].

As informantes continuaram a falar sobre suas preocupações em relação à performance sexual. D as que disseram que já se preocuparam ou se preocupam sobre sua performance (10), razões tais como "pensar demais; estar bêbada ou sóbria; agradar uma parceira sexual nova; não estar no clima; silêncio durante 0 sexo; estresse e cansaço; e não perceber que a parceira está satisfeita" foram dadas como obstáculos para parformance sexual ótima. Ao pedirmos para que as informantes classificassem sua performance sexual, sendo 10 excelente, a menor nota foi 7.5, com a maioria das informantes se classificando entre 8 e 10. C ontudo, enquanto muitas se vangloriaram de sua performance excelente, al gumas relataram preocupações que limitavam níveis similares de performance:

Q uando eu vejo, sinto ou percebo que ela não ficou satisfeita ou ela me diz que eu não fiz alguma coisa certo. [femme, 30].

A maior parte do tempo eu me preocupo porque estamos fazendo sexo sem proteção e eu não estou dando tudo. [femme, 28].

\section{Conclusões}

A lacuna na pesquisa sobre lésbicas na África do Sul e em relação ao que significa ser lésbica é ampla. Estudos que as tomaram por objeto partiram do pressuposto de que esse grupo extremamente diverso é homogêneo. M ulheres em relações eróticas com pessoas do mesmo sexo se definem e se identificam de várias formas. Enquanto algumas escolhem se identificar como lésbicas, outras assumem papéis relacionados a gênero como suas formas de identificação. Essas formas de identificação têm vários significados e práticas com relação à sexualidade e performance sexual.

Enquanto essa lacuna na pesquisa sobre lésbicas se amplia, outra ainda mais ampla continua a existir em relação aos estudos sobre sexualidade lésbica e sexo seguro. Pesqui sas limitadas nessa área apenas analisaram práticas de testagem de HIV e prevalência do HIV na comunidade gay e lésbica. As análises mostram taxas al tas de infecção por H IV na comunidadelésbica mas não exploram o porquê dessa situação. Como as lésbicas não são vistas como estando em risco, elas não são alvo das diversas campanhas de prevenção do H IV no país. I sso tem um impacto 
nas práticas de testagem; acesso à informação sobre transmissão de H IV entre essas mulheres; e a prática de formas mais seguras de sexo.

Asinformantes deste estudo mostram que existe uma preocupação geral com o H IV ea segurança em relação ao sexo com uma mulher. Como muitas pessoas desconhecem seu statussorológico efaltam métodos de proteção (sexy eagradáveis) para estas mulheres, a Aids continua a ser uma preocupação que afeta tanto 0 prazer equanto a performance.

\section{Referências}

BLYTH , S. An exploration of accounts of lesbian identities. D issetação (M estrado) - University of CapeTown, Cidade do Cabo, 1989.

GEVISSER, M. A different fight for freedom: A history of South African gay and lesbian organizationsfrom the 1950s to 1990s. In: GEVISSER, M.; CAM ERO O N , E. (eds). D efiant D esire. Joanesburgo: Ravan Press, 1994.

KEN D ALL, J. W hen a woman lovesawoman in Lesotho. In: M URRAY, S.; RO SCOE, W. (eds). Boy-wives and female husbands. studies of African homosexualities. N ew York: St M artin's Press, 1998.

M U H O LI, Z. Thinking through lesbian rape. Agenda, n. 61, p. 116-125, 2004.

RAM PERSAD H , Y. H IV/Aids ratein Gauteng at 30\%. M ail\& Guardian online. Joanesburgo, South Africa, 6 out. 2005.

SHEFER, T.; POT GIETER, C. Sexualities. In: SH EFER, T.; BO O N ZAIER, F.; KIGUWA, P. (eds). Thegender of psychology. C apeTown: U CT Press, 2006.

WELLS, H .; PO LDERS, L. Anti-gay hatecrimes in South Africa: prevalence, reporting practices, and experiences of thepolice. Agenda, n. 67, p. 20-28, 2006.

. H IV and sexually transmitted infections (ST IS) among gay and lesbian peoplein G auteng: prevalenceand testing practices O UT LGBT Well Being: Pretoria, 2006.

WELLS, H., KRU GER, T. and JUD GE, M . 2006. Experiencesand dimensions of power: discussions with lesbian women. OUT LGBT Well Being: Pretoria.

WIERIN GA, S.E. Globalization, love, intimacy and silence in a working class butch/Fem community in Jakarta. ASSR Working Paper 05/08, 2005.

ZIM M ERM AN , B. What hasnever been: an overview of lesbian feminist literary criticism. Feminist Studies, v. 7, n. 3, p. 451-475, 1981. 


\section{N otas}

*T ítulo original: All Sexed U p: young black lesbian women's responses to safe(r) sex in J ohannesburg, South Africa

${ }^{1}$ Partnered, é um termo usado nos círculos lésbicos em Johannesburg para se distinguir entre a pessoa que está disponível para outras (pode ter várias outras parcei ras sexuais) e a que geralmente não está disponível (em um relacionamento, portanto, com uma parceira sexual), mas que poderia se tornar disponível para outras.

${ }^{2}$ Woman-loving-woman - W LW, no original. (N ota da tradutora). 


\section{Abstract}

All Sexed U p: young black lesbian women's responses to safe( $r$ ) sex in J ohannesburg, South Africa

Lesbian women's health and sexual health is a theme not generally discussed in our societies. Women's' health issues are generally classified under one umbrella, and exclude some of the concerns specific to lesbian women. Lesbian women in general do not have the same health-seeking behaviours as heterosexual women. This is due to a number of reasons including: lack of knowledge about lesbian sexual health and sexual risk, fear of stigmatization by service providers, and the "coming out" process to unfamiliar and sometimes unsympathetic healthrelated service providers. Furthermore, limited research on lesbians and lesbian health in South Africa makes it difficult for lesbian women to know what sexual health issues affect them specifically, where and how to address these issues. There is a general misconception that safe sex issues do not affect lesbian women as much as they affect heterosexual women. The paper presents views of a group of young self-identified lesbian women in South Africa between the ages of 18 and 35 . Through self-administered questionnaires and discussions these women share their experiences and thoughts of lesbian (safe) sex and how they have related and continue to relate sexually with other women in the time of HIV and Aids.

> Key words: Lesbian; gender; identity; sexuality; HIV and Aids, South Africa. 